\title{
Penentuan Lama Waktu Istirahat Pekerja Berdasarkan Beban Kerja Fisik pada PT. Perkebunan Nusantara 1 PKS Pulau Tiga
}

\author{
Yusnawati $^{1}$, Yusri Nadya ${ }^{2}$, Ilham Syahputra ${ }^{3}$ \\ ${ }^{1,2,3}$ Jurusan Teknik Industri, Universitas Samudra, Meurandeh - Langsa, Aceh \\ 1yuznanice@gmail.com
}

\begin{abstract}
Energy recovery is very important to note during the working process to avoid fatigue. One of the factors that can affect energy recovery is rest time. Workers with heavy workloads require the period and frequency of breaks that are different from workers with a light workload. Workers with heavy workload cederung get tired and thus require longer rest periods and more often. This research was conducted at PT. Perkebunan Nusantara 1 PKS Pulau Tiga in the sorting Fruit Bunch Oil (TBS), as for the purpose of this study was to assess the workload of workers and clarify the workload by comparing the workload standards, determine the length of rest time workers appropriate in the sorting TBS that they can work with optimum conditions so that the quality of the raw material processed is maintained, and determine the level of energy consumption for the workers at the sorting TBS so that they can work with optimum conditions so that the quality of raw materials TBS maintained, and determine the level of energy consumption of the workers at the sorting TBS, Measurement of physical workload is a simple method to determine the length of time off based on the pulse of current workers to work and rest. From the calculation that the workload (CVL), the worker is greater than 30 percent and categorized at a moderate level and to work in a short time and needed repair. The timing of the break based on the workload is determined by physiological approach. Based on the physiological approach, that breaks given by the manufacturer is not sufficient when compared to the workload of workers sorting the fruit, where the optimal long rest periods for these workers is over 73 minutes or as long as 1,2 hours.
\end{abstract}

Keywords: Workload, Physiological, Break Time

\section{PENDAHULUAN}

PT. Perkebunan Nusantara I PKS Pulau Tiga merupakan perusahaan yang bergerak dalam bidang pengolahan tandan buah segar (TBS) kelapa sawit menjadi crude palm oil (CPO) dan palm kernel oil (PKO). Proses kerja yang ada pada perusahaan tersebut terdiri dari beberapa stasiun, diantaranya adalah stasiun penerimaan TBS, stasiun perebusan (sterilization), stasiun penebahan (threshing), stasiun pengempaan (pressing), stasiun klarifikasi, stasiun pengolahan biji, dan stasiun pengolahan inti. Setelah dilakukan observasi ternyata pada stasiun penerimaan TBS khususnya dibagian sortasi TBS mengalami beban kerja yang berlebih yang ditandai dengan rasa lelah yang berlebih yang dirasakan oleh pekerja. Pada bagian sortasi TBS pekerja melakukan pekerjaannnya dengan cara memilih dan memindahkan TBS secara manual, apabila para pekerja pada 
bagian sortasi TBS mengalami kelelahan, maka hal itu akan mengakibatkan menurunnya produktifitas dan konsentrasi pekerja pada bagian TBS.

Saat ini PT. Perkebunan Nusantara I Pulau Tiga memiliki 3 shift kerja. Untuk shift 1, dimulai dari pukul 7.00 sampai pukul 14.00, shift 2 dimulai pada pukul 14.00 sampai pukul 22.00 dan pada shift 3 dari pukul 22.00 sampai dengan pukul 7.00. Pada stasiun penerimaan buah khususnya pada bagian sortasi hanya beroperasi pada shift pertama saja, dimana waktu kerja yang dimiliki pada shift 1 yaitu selama 7 jam dengan waktu istirahat selama 1 jam. Melalui pengamatan yang dilakukan, ini mengakibatkan pekerja berkerja diluar kapasitas normal. Apabila pekerja bekerja diluar kapasitas normal maka optimalitas kerja tidak tercapai baik kualitas maupun kuantitasnya. Oleh sebab itu, untuk menyesuaikan kapasitas kerja dengan beban kerja fisik pekerja dilakukan penelitian penentuan lama waktu istirahat pekerja berdasarkan beban kerja fisik pada PT. Perkebunan Nusantara 1 PKS Pulau Tiga.

Penelitian ini bertujuan menilai beban kerja pekerja dan mengklarifikasi beban kerja dengan membandingkan dengan beban kerja standar, menentukan lama waktu istirahat pekerja yang sesuai pada bagian sortasi TBS agar mereka bisa bekerja dengan kondisi optimal sehingga kualitas dari bahan baku olahan tetap terjaga, dan mengetahui tingkat konsumsi energi bagi pekerja pada bagian sortasi TBS.

\section{TINJAUAN PUSTAKA}

\subsection{Penilaian Beban Kerja Fisik}

Salah satu kebutuhan umum dalam otot adalah oksigen yang dibawa oleh darah ke otot untuk pembakaran zat dalam menghasilkan energi. Menteri tenaga kerja memalui kep. No. 51 tahun 1999 menetapkan kategori beban kerja menurut kebutuhan kalori adalah sebagai berikut:
Beban kerja ringan
: 100-200 Kkal/jam
Beban kerja menengah $\quad: 200-350 \mathrm{Kkal} / \mathrm{jam}$
Beban kerja berat : : :350-500 Kkal/jam

Ada beberapa metode yang bisa dilakukan dalam menilai beban kerja fisik, salah satunya yaitu dengan menghitung denyut nadi pekerja selama bekerja. Pengukuran denyut nadi selama bekerja merupakan suatu metode untuk menilai cardiovasculair strain dengan pengukuran 10 denyut (Kilbon, 1992) dimana dengan metode ini dapat dihitung berdasarkan Persamaan 1.

$$
\text { Denyut Nadi }=\frac{10 \text { Denyut }}{\text { Waktu Hitungan }} \times 60
$$

Kepekaan denyut nadi terhadap perubahan pembebanan yang diterima tubuh cukup tinggi. Denyut nadi akan segera berubah seirama dengan perubahan pembebanan fisik (Kurniawan, 1995). Beban kerja fisik tidak hanya ditentukan oleh jumlah kJ (Kilo Joule) yang dikonsumsi, tetapi juga ditentukan oleh jumlah otot yang terlibat dan beban statis yang diterima serta tekanan panas dari lingkungan kerjanya yang dapat menigkatkan denyut nadi. Berdasarkan hal tersebut maka denyut nadi lebih mudah dan dapat menghitung indeks beban kerja. Astrand dan Rodahl (1997) menyatakan bahwa denyut nadi memiliki hubungan linier yang tinggi dengan asupan oksigen dalam waktu kerja. Dan salah satu cara yang sederhana dalam menghitung denyut nadi adalah merasakan denyutan dipergelangan tangan.

Denyut nadi untuk mengestimasi indeks beban kerja fisik terdiri dari beberapa jenis diantaranya:

1. Denyut Nadi Istirahat (DNI) adalah rerata denyut nadi sebelum pekerjaan dimulai.

2. Denyut Nadi Kerja (DNK) adalah rerata denyut nadi selama bekerja.

3. Nadi Kerja (NK) adalah selisih antara denyut nadi istirahat dengan denyut nadi kerja. 
Peningkatan denyut nadi mempunyai peran yang sangat penting dalam peningkatan cardiac output dari istirahat sampai kerja maksimum. Penigkatan yang potensial dalam denyut nadiistirahat sampai kerja maksimum tersebut oleh Rodahl (1989) dalam Ratna (2007: 14) didefinisikan sebagai Heart Rate Reserve (HR Reserve). HR Reserve tersebut diekspresikan dalam presentase yang dapat dihitung berdasarkan Persamaan 2.

$$
\% \text { HR Reserve }=(\text { DNK }- \text { DNI }) /(\text { DNMax }- \text { DNI }) \times 10
$$

Keterangan:

DNK : Denyut nadi kerja

DNI : Denyut nadi istirahat

DNMax : Denyut nadi maksimum, (220 - umur) untuk laki-laki dan (200 - umur) untuk perempuan

Lebih lanjut, Manuaba dan Vanwonteerghem (1996) menentukan klarifikasi beban kerja berdasarkan peningkatan denyut nadi kerja yang dibandingkan dengan denyut nadi maksimum karena beban kerja kardiovaskuler (cardiovasculer load = \%CVL) yang dihitung dengan Persamaan 3.

$$
\% C V L=100 X(D N K-D N I) / D N M a x-D N I
$$

Dari hasil perhitungan \% CVL tersebut kemudian dibandingkan dengan klasifikasi yang telah ditetapkan seperti yang di tampilkan pada Tabel 1.

Tabel 1. Klasifikasi Berat Ringan Keja Berdasarkan \% CVL

\begin{tabular}{cc}
\hline$\%$ CVL & Keterangan \\
\hline$<30 \%$ & Tidak terjadi kelelahan \\
$30 \%-<60 \%$ & Diperlukan perbaikan \\
$60 \%-<80 \%$ & Kerja dalam waktu singkat \\
$80 \%-<100 \%$ & Diperlukan tindakan segera \\
$>100 \%$ & Tidak diperbolehkan beraktivitas
\end{tabular}

\subsection{Metabolisme Energi}

Setiap hari manusia selalu terlibat dengan kegiatan bekerja yang memerlukan tenaga, kita harus memperhatikan bagaimana mengatur kegiatan kerja yang sedemikian rupa agar posisi tubuh saat bekerja atau bergerak dalam keadaan nyaman tanpa mempengaruhi hasil kerja. Tubuh manusia dianggap sebagai suatu mesin dimana untuk melaksanakan aktivitas dibatasi atas serangkaian hukum alam. Kemampuan manusia untuk melaksanakan berbagai kegiatan bergantung kepada struktur fisik tubuh yang terdiri dari struktur tulang otot-otot rangka, sistem syaraf dan proses metabolisme. Dua ratus enam tulang manusia membentuk rangka yang berfungsi untuk melindungi dan melaksanakan kegiatan fisik. Tulang-tulang tersebut dihubungkan dengan sendi-sendi tulang yang terdiri atas gumpalan-gumpalan serabut yang dapat berkontraksi. Serabut otot ini berfungsi untuk mengubah energi kimia menjadi energi mekanik, kegiatan otot ini dikontrol oleh sistem syaraf sehingga kegiatan secara keseluruhan dapat berlangsung dengan baik.

Semua dari kegiatan manusia membutuhkan tenaga, tenaga ini diperoleh karena adanya proses metabolisme didalam otot, yaitu berupa kumpulan-kumpulan dari proses kimia yang mengubah bahan makanan menjadi dua bentuk, yaitu kerja mekanis dan panas. Makanan yang mengandung glikogen mengalir kedalam tubuh melalui peredaran darah. Setiap kotraksi otot selalu diikuti oleh reaksi kimia (oksidasi glukosa) yang mengubah glikogen tersebut menjadi tenaga, panas, dan asam laktat (produk sisa). Dalam tubuh dikenal fase pemulihan yaitu suatu proses mengubah asam laktat menjadi glikogen 
kembali dengan adanya oksigen dari pernapasan, sehingga memungkinkan otot-otot bisa bergerak secara kontinu sehingga keseimbangan kerja dapat dicapai dengan baik.

\section{METODOLOGI PENELITIAN}

Metode yang digunakan dalam penelitian ini dalah penelitian deskriptif, yaitu penelitian yang berusaha untuk memaparkan pemecahan masalah terhadap suatu masalah yang ada sekarang secara sistematis dan actual berdasarkan data-data. Jadi penelitian inimeliputi proses pengumpulan, penyajian, danpengolahan data, serta pemecahan masalah.

\subsection{Tempat dan Waktu Penelitian}

Lokasi penelitian dilakukan di PT. Perkebunan Nusantara I Pulau Tiga, Aceh Tamiang. Penelitian ini dilakukan dalam jangka waktu 3 bulan.

\subsection{Objek penelitian} sortasi buah.

Objek penelitian dalam dalam penelitian ini adalah pekerja yang bekerja dibagian

\subsection{Instrumen penelitian}

1. Buku catatan

Adapun instrumen yang digunakan untuk mengumpulkan data adalah:

Buku catatan merupakan instrumen yang digunakan untuk mencatat hasil wawancara tentang hal-hal yang berkaitan dengan perusahaan.

2. Stopwatch

Stopwacth merupakan alat yang digunakan untuk mengukur waktu denyut nadi pekerja saat istirahat dan ketika bekerja dilapangan.

3. Blood Pressure

Blood pressure merupakan alat yang digunakan untuk mengukur tekanan darah dandenyut jantung pekerja saat istirahat dan ketika bekerja di lapangan.

\subsection{Metode Pengumpulan Data}

Data yang dibutuhkan dalam penelitian ini terdiriatas data primer dan data sekunder, yaitu :

a. Data Primer

b. Data Sekunder

Data primer dalam penelitian ini adalah data denyut nadi pekerja.

Data sekunder adalah data yang diperoleh dari dokumen yang tersedia dari perusahaan serta hasil wawancara dengan pimpinan atau karyawan untuk mendapatkan informasi dan data yang berhubungan dengan penelitian. Pengumpulan data sekunder berupa pencatatan historis perusahaan, aliran proses produksi, umur, jam kerjapekerjadan jam istirahat yang diterapkan oleh perusahaan.

\subsection{Pengolahan data}

Pengolahan data yang dilakukan dalam penelitian ini adalah:

3.5.1. Menghitung denyut nadi pekerja

Dalam mengukur denyut jantung setiap pekerja, peneliti menggunakan alat blood pressure, dimana hasil dari pengukuran tersebut dalam satuan denyut/menit.

\subsubsection{Menghitung uji keseragaman data}

Uji keseragaman data dilakuka nuntu kmelihat data yang terkumpul apakah sudah

berada dalam batas kendali. Dalam penelitian ini, tingkat kepercayaan yang 
digunakanadalah 95\% dan tingkat ketelitian 5\%. Adapun persamaan yang di digunakan adalah sebagai berikut:

$$
\begin{aligned}
& B K A=\mu+k \sigma x \\
& B K B=\mu-k \sigma x
\end{aligned}
$$

Keterangan:

$\mathrm{BKA}=$ Batas kendali atas

$\mathrm{BKB}=$ Batas kendali bawah

3.5.3. Menghitung Jumlah Energi yang Dikeluarkan Oleh Pekerja

Menghitung jumlah energi yang dikeluarkan oleh pekerja dapat digunakan dengan rumus seperti pada Persamaan 5 berikut:

$$
y=1.80411-0.0229038 X+4.71733 \times 10^{-4} X^{2}
$$

Keterangan:

$\mathrm{Y} \quad: \quad$ Energi (Kkal/menit)

$\mathrm{X} \quad$ : $\quad$ Kecepatan denyut jantung (denyut/menit)

\subsubsection{Menghitung Waktu Istirahat yang Dibutuhkan Pekerja}

Setelah mengetahui besarnya konsumsi energi yang dikeluarkan oleh pekerja, kemudian dilanjutkan dengan menghitung waktu yang dibutuhkan untuk beristirahat, dengan menggunakan Persamaan 6.

$$
R=\frac{T(\bar{K}-S)}{\bar{K}-1.5}
$$

Keterangan:

$\mathrm{R}$ : Waktu istirahat yang diperlukan (menit)

$\mathrm{T}$ : Total waktu yang digunakan untuk kerja (menit)

$\overline{\mathrm{K}}$ : Rata-rata energi yang dikonsumsikan untuk kerja (Kkal/menit)

$\mathrm{S}$ : Standar beban kerja normal yang direkomendasikan $(\mathrm{S}=4 \mathrm{Kkal} / \mathrm{menit}$ untuk wanita dan $\mathrm{S}=5 \mathrm{Kkal} /$ menit untuk pria)

\subsubsection{Analisis pemecahan masalah}

Pada tahap ini hasil dari pengolahan data akan dinilai berdasarkan beban kerja pekerja dengan menggunakan beban kerja fisik. Hasil penilaian digunakan untuk merancang waktu istirahat untuk pekerja pada jam kerja tertentu berdasakan aktivitas pekerja.

\section{HASIL DAN PEMBAHASAN}

\subsection{Uji Keseragaman Data}

Uji keseragaman data para pekerja bagian sortasi buah TBS fase persiapan dapat dilihat pada Gambar 1.

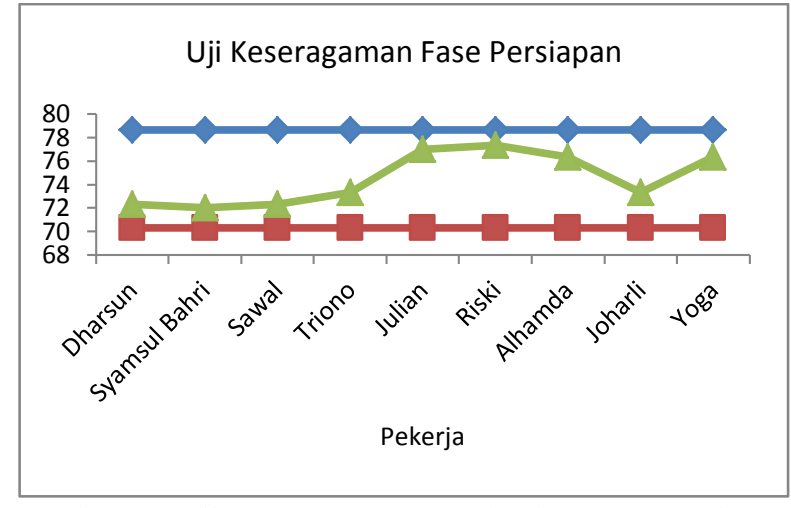

Gambar 1. Uji Keseragaman Pekerja Fase Persiapan. 
Dari Gambar 1 dapat dilihat bahwa data denyut jantung pekerja berada dalam batas kontrol, sehingga dapat disimpulkan bahwa data denyut jantung pekerja fase persiapan di bagian sortasi buah adalah seragam

Uji keseragaman data para pekerja bagian sortasi buah TBS fase bekerja dapat dilihat pada Gambar 2.

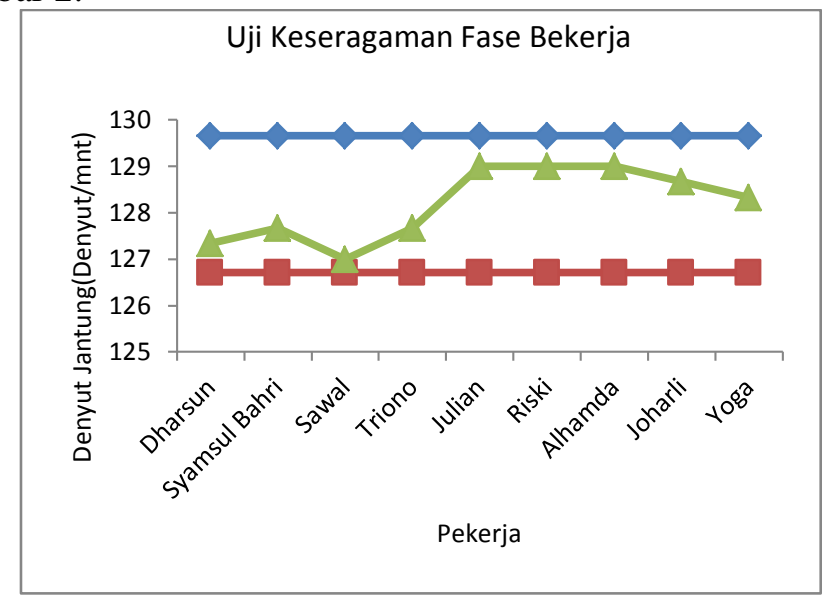

Gambar 2. Uji Keseragaman Pekerja Fase Bekerja

Dari Gambar 2 dapat dilihat bahwa data denyut jantung pekerja berada dalam batas kontrol, sehingga dapat disimpulkan bahwa data denyut jantung pekerja fase bekerja di bagian sortasi buah adalah seragam

Uji keseragaman data para pekerja bagian sortasi buah TBS fase persiapan dapat dilihat pada Gambar 3.

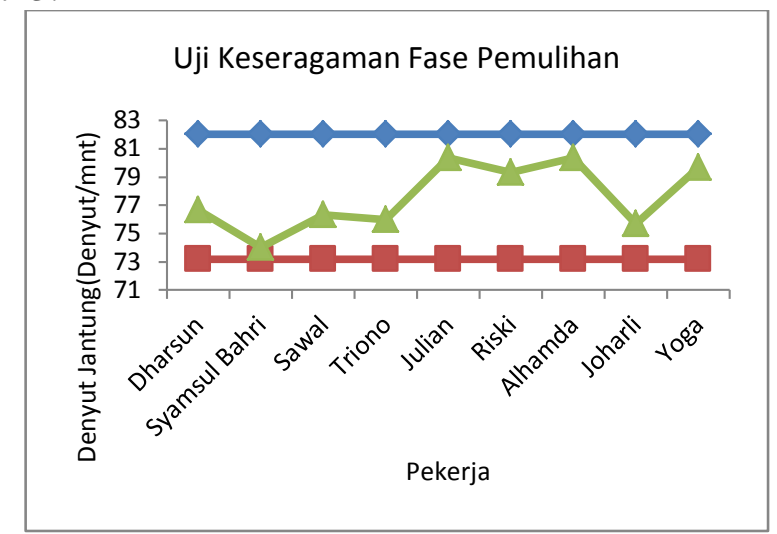

Gambar 3. Uji Keseragaman Pekerja Fase Pemulihan

Dari Gambar 3 dapat dilihat bahwa data denyut jantung pekerja berada dalam batas kontrol, sehingga dapat disimpulkan bahwa data denyut jantung pekerja fase pemulihan di bagian sortasi buah adalah seragam.

\subsection{Perhitungan Konsumsi Oksigen}

Adapun rekapitulasi perhitungan konsumsi oksigen pekerja di bagian sortasi TBS dapat dilihat pada Tabel 2.

Tabel 2. Rekapitilasi Rata-rata Konsumsi Energi Pekerja

\begin{tabular}{ccc}
\hline No & Nama & $\begin{array}{c}\text { Rata-rata Konsumsi } \\
\text { Energi (Liter/Menit) }\end{array}$ \\
\hline 1 & Dharsun & 0,84 \\
2 & Syamsul bahri & 0,85 \\
3 & sawal & 0,84
\end{tabular}




\begin{tabular}{lcc}
4 & Triono & 0,85 \\
5 & Julian & 0,9 \\
6 & Riski & 0,9 \\
7 & Alhamda & 0,9 \\
8 & Joharli & 0,85 \\
9 & Yoga & 0,9 \\
\hline & Rata-rata & 0,87
\end{tabular}
pada Gambar 4.

Berdasarkan Tabel 2, maka grafik konsumsi energi setiap pekerja dapat dilihat

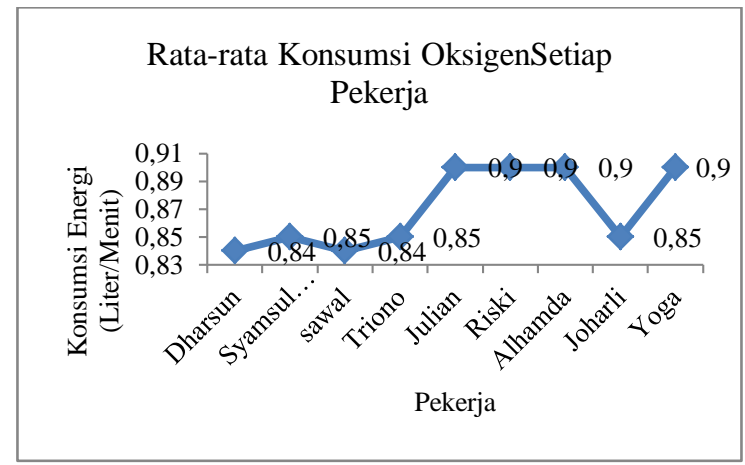

Gambar 4. Konsumsi Energi Pekerja

Dari Gambar 4 dapat dilihat bahwa konsumsi Oksigen pekerja berkisar 0,84 s.d 0,9 Liter/Menit. Hal ini mengindikasikan bahwa para pekerja memerlukan oksigen dua kali lipat dari kondisi normal. Pada level ini pekerja sangat mudah mengalami kelelahan dan membutuhkan asupan banyak air untuk menyeimbangkan proses metabolisme dalam tubuh. Adapun kondisi lain yang tidak diharapkan adalah dehidrasi karena pekerja mengalami kekurangan cairan. Rekapitulasi \%CVL dan tindakan yang diperlukan untuk setiap pekerja dapat dilihat pada Tabel 3.

Tabel 3. Persen CVL dan Kriteria Tindakan Setiap Pekerja

\begin{tabular}{|c|c|c|c|c|c|}
\hline Pekerja & DNI & DNK & $\mathrm{DN}_{\max }$ & $\begin{array}{c}\% \\
\text { CVL }\end{array}$ & Kategori \\
\hline Dharsun & 74.50 & 127.33 & 161 & $61.08 \%$ & Kerja dalam waktu singkat \\
\hline Syamsul & 73 & 127.67 & 177 & $52.57 \%$ & Diperlukan perbaikan \\
\hline Sawal & 74.33 & 127 & 171 & $54.48 \%$ & Diperlukan perbaikan \\
\hline Triono & 74.67 & 127.67 & 177 & $51.79 \%$ & Diperlukan perbaikan \\
\hline Julian & 78.67 & 129 & 199 & $41.83 \%$ & Diperlukan perbaikan \\
\hline Riski & 78.33 & 129 & 200 & $41.65 \%$ & Diperlukan perbaikan \\
\hline Alhamda & 78.33 & 129 & 199 & $41.99 \%$ & Diperlukan perbaikan \\
\hline Joharli & 74.50 & 128.67 & 184 & $49.47 \%$ & Diperlukan perbaikan \\
\hline Yoga & 78 & 128.33 & 194 & $43.39 \%$ & Diperlukan perbaikan \\
\hline
\end{tabular}

Dari Tabel 3 diperoleh bahwa hasil kategori tindakan pekerja adalah bekerja dalam waktu singkat dan diperlukan perbaikan terhadap seluruh pekerja yang diamati. Adapun perbaikan yang dilakukan yaitu dengan memberikan waktu istirahat pendek 
kepada seluruh pekerja agar mengurangi beban kardiovaskuler (\%CVL). Total waktu istirahat yang diusulkan dapat dilihat pada Tabel 4.

Tabel 4. Total Waktu Istirahat Yang Diusulkan

\begin{tabular}{cc}
\hline Nama & $\begin{array}{c}\text { Total Waktu Istirahat } \\
\text { (menit) }\end{array}$ \\
\hline Dharsun & 69.6 \\
Syamsul Bahri & 70.8 \\
Sawal & 69 \\
Triono & 70.8 \\
Julian & 76.2 \\
Riski & 76.2 \\
Alhamda & 76.2 \\
Joharli & 75 \\
Yoga & 73.8 \\
\hline Rata-rata & 73.1 \\
\hline
\end{tabular}

\section{KESIMPULAN}

Kesimpulan yang dapat diambil dalam penelitian ini adalah bahwa berdasarkan jadwal kerjakaryawan, waktu istirahat yang diberikan oleh pihak pabrik belum mencukupi jika dibandingkan dengan beban kerja dari pekerja sortasi TBS, dimana lama waktu istirahat yang optimal untuk para pekerja tersebut yaitu selama 1.2 jam.

Jumlah pengeluaran energi setiap pekerja diantaranya yaitu Dharsun (5.84 $\mathrm{Kkal} / \mathrm{menit}$ ), Syamsul Bahri (5.86 Kkal/menit), Sawal (5.83 Kkal/menit), Triono (5.86 $\mathrm{Kkal} / \mathrm{menit})$, Julian (5.94 Kkal/menit), Riski (5.94 Kkal/menit), Alhamda (5.94 $\mathrm{Kkal} / \mathrm{menit})$, Joharli (5.92 Kkal/menit), dan Yoga $(5.90 \mathrm{Kkal} / \mathrm{menit})$. Dimana semua pekerja dikategorikan pada tingkat moderat.

\section{DAFTAR PUSTAKA}

Bakri. 2011. Manajemen Ergonomi. UNIBA. Surakarta

Halander Martin. 2006. A Guide To Human Factors And Ergonomics. Taylor\&Franc: New York.

Kusmindari dkk. 2011. Pengaruh musik terhadap beban kerja fisik karyawan di bagian produksi. Universitas Bida Darma: Palembang

Nurmianto Eko. 2006. Ergonomi: Konsep dasar dan aplikasinya. Guna Widya: Surabaya.

Phaesant stephen. 2003. Body Space, Antropometry, Ergonomics And Design Of Work. Taylor\&Franc:London.

Purwaningsih Ratna dan Purnawan. 2007. Ergonomi industri. Universitas Diponegoro Semarang.

Wignojosoebroto Sritomo.2006. Ergonomi Studi Gerak dan Waktu. Gunawdya: Surabaya.

Yanto. 2011. Ergonomi:Studi Waktu dan Gerakan untuk Analisa dan Perbaikan Kerja. Unika Atmajaya: Jakarta. 